\title{
Concepções sobre imagem corporal da mulher negra entre alunas do ensino médio em Teresina/PI
}

\author{
Body image of black woman between high school \\ conceptions about the students in Teresina / PI
}

\section{Concepciones sobre imagen corporal de la mujer negra entre alumnas de la enseñanza medio en Teresina / PI}

\author{
(iD) Francisco Elismar da Silva Junior \\ Universidade Federal do Piauí, Teresina, Piauí, Brasil \\ e-mail: franciscoafoxa@gmail.com \\ iD) Fábio Soares da Costa \\ Universidade Federal do Piauí, Teresina, Piauí, Brasil \\ e-mail: fabiocosta@ufpi.edu.br \\ (iD) Janete de Páscoa Rodrigues \\ Universidade Federal do Piauí, Teresina, Piauí, Brasil \\ e-mail: janetepascoa@ufpi.edu.br
}

\begin{abstract}
Resumo: Objetivou-se, neste estudo, analisar concepções de alunas do ensino médio acerca da imagem corporal da mulher negra. Empregou-se os métodos estatístico e descritivo, sendo pesquisadas 26 alunas. Nos resultados, constatou-se que a maioria das alunas não considera qualquer aspecto corporal da mulher negra como feio. Contudo, existem opiniões que suscitam estigmas sobre a noção de beleza voltada para padrões eurocêntricos. Concluiu-se que a concepção de imagem corporal das alunas encontra-se permeada por incertezas e sentidos de beleza fluidos e contraditórios, construídos na ausência de uma educação corporal consistente, capaz de abolir comportamentos e concepções preconceituosas.
\end{abstract}

Palavras-chave: Corpo negro. Mulher. Ensino Médio. Imagem Corporal. 
Abstract: The objective of this study was to analyze conceptions of high school students about the black woman's body image. The statistical and descriptive methods were employed, with 26 students being surveyed. In the results, it was verified that the majority of the students does not consider any corporal aspect of the black woman as ugly. However, there are opinions that raise stigmas about the notion of beauty focused on Eurocentric standards. It was concluded that the students' body image conception is permeated by fluid and contradictory uncertainties and senses of beauty, built in the absence of a consistent corporal education capable of abolishing prejudiced behaviors and conceptions.

Keywords: Black body. Woman. High school. Body image

Resumen: Se objetivó en este estudio, analizar concepciones de alumnas de la enseñanza media acerca de la imagen corporal de la mujer negra. Se emplearon los métodos estadístico y descriptivo, siendo investigadas 26 alumnas. En los resultados, se constató que la mayoría de las alumnas no considera ningún aspecto corporal de la mujer negra como feo. Sin embargo, existen opiniones que suscitan estigmas sobre la noción de belleza orientada hacia patrones eurocéntricos. Se concluyó que la concepción de imagen corporal de las alumnas se encuentra permeada por incertidumbres y sentidos de belleza fluidos y contradictorios, construidos en la ausencia de una educación corporal consistente, capaz de abolir comportamientos y concepciones preconcebidas.

Palabras clave: Cuerpo negro. Mujer. Enseñanza Media. Imagen Corporal

Submetido em: 20-08-2019

Aceito em: 15-01-2021 
Concepções sobre imagem corporal da mulher negra entre alunas do ensino médio... Francisco Elismar da Silva Junior • Fábio Soares da Costa • Janete de Páscoa Rodrigues

\section{Introdução}

A imagem corporal é uma construção humana que está relacionada a vários aspectos, como o cognitivo, afetivo, social/cultural e motor. Está intimamente ligado ao conceito de si próprio, e às diversas interações entre o indivíduo e o meio em que vive (ADAMl et al., 2005). A discussão sobre o corpo se faz necessária dentro das escolas por estas serem lócus de formação, local de relacionamento com a vida e com outros corpos. Nesse sentido, no que se refere à questão étnico-racial, observa-se que existe um distanciamento entre o que se deve fazer e o que é feito a respeito da lei 10.639/03 (BRASIL, 2003), que orienta as escolas a incluir a história da África e dos afrodescendentes em seus currículos. Isso proporciona, muitas vezes, uma visão distorcida e reforça imagens pejorativas do corpo negro e suas formas de expressão.

Por isso, o objetivo deste estudo consistiu em analisar concepções de alunas do ensino médio de uma escola pública de Teresina - PI acerca da imagem corporal da mulher negra. Assim, a questão norteadora da pesquisa foi: Quais as percepções de alunas do ensino médio de uma escola pública de Teresina - PI sobre o a imagem corporal da mulher negra?

A imagem corporal é constituída a partir de um conjunto de aspectos cognitivos, sociais e afetivos que, quando inseridos em uma determinada cultura, sofre modificações e gera padrões de comportamentos, que podem ser negativos e levar a distorções psicológicas, alimentares e corporais. Segundo Costa e Machado (2014), ela também pode ser definida "como a maneira pela qual o indivíduo se percebe e se sente em relação ao seu próprio corpo".

A mídia tem um importante papel na construção da imagem corporal, pois é por intermédio de suas narrativas compostas de sons, imagens e discursos que se formam espaços de criação e de sentidos na vida diária, por contribuírem para a constituição de pensamentos e ações dos indivíduos sociais (FELIPE; FRANÇA, 2017). 
Concepções sobre imagem corporal da mulher negra entre alunas do ensino médio... Francisco Elismar da Silva Junior • Fábio Soares da Costa • Janete de Páscoa Rodrigues

Sobre a construção de uma imagem corporal, é importante ressaltar que "as influências que os meios social, econômico e cultural exercem sobre as formas de o homem perceber o corpo, seu e do outro, possibilitam uma série de variações nas maneiras de se compreender e tratar o corpo" (SILVA; SILVA; LÜDORF, 2015, p. 674).

Nas narrativas da história e da cultura negra no Brasil, temos que considerar o que se diz sobre a corporeidade negra. O corpo e o cabelo mostram figurativamente os princípios fundamentais da vida coletiva. Entende-se que a corporeidade se apresenta como um arquivo discursivo que simboliza aquilo que uma sociedade deseja ser ou negar (FELIPE; FRANÇA, 2017).

A idealização do corpo como objeto da cultura questiona a noção de naturalidade a este atribuída, assim, o corpo biológico é fundamentalmente natural, o que atribui à condição humana um conceito genérico de universalidade. Em troca, esse corpo é impactado pela cultura, que retira deste a universalidade, ao promover a emergência de particularidades que atribuem ao ser humano alteridade, identidade e diferença (FREITAS, 2016).

Quando tratamos do corpo negro percebemos uma desvalorização e deformação nos conceitos e padrões construídos previamente por culturas africanas. Para Silva (2016), culturas negras subjugadas pelo colonialismo europeu sofreram e continuam sofrendo investidas para que se calem, desconstruam-se, desapareçam, visando a sua integração às margens do domínio da cultura eurocêntrica, destinando sempre aos guetos da sociedade essa parcela da população.

Ao tratar especificamente das mulheres negras, observamos que os sentidos ofertados pelas características desses corpos estão intimamente relacionados à cor da pele, às formas do corpo, aos cabelos e aos componentes do rosto, tais como nariz, boca e olhos, que se tornam marcadores indenitários específicos dessas pessoas. Assim, para Nogueira (1999), discutir sobre o corpo negro feminino implica pensarmos o corpo enquanto signo, como um 
Concepções sobre imagem corporal da mulher negra entre alunas do ensino médio... Francisco Elismar da Silva Junior • Fábio Soares da Costa • Janete de Páscoa Rodrigues

ser que constrói um arcabouço social de forma a dar-lhe um sentido específico, que certamente irá variar de acordo com os mais diferentes modelos sociais.

Quando falamos em ensino médio, nos referimos aos adolescentes. Portanto, partimos do ponto de que não podemos considerar a adolescência como uma fase que compartilha mudanças e comportamentos predeterminados, e sim que é uma etapa na qual as alterações de comportamento estão ligadas à cultura/sociedade em que estão inseridos (GODOY; VIEIRA; MOURÃO, 2015).

Desse modo, a educação básica é essencial para a formação dos indivíduos, pois a assimilação e o entendimento das diversas culturas e possibilidades de representações corporais deveriam ser apropriados pelo sistema educacional. Um meio para se alcançar isso é através dos estudos sobre corporeidade. Portanto, a apreciação entre corpo e corporeidade não é apenas uma realidade biológica, mas sim uma construção cultural e histórica que transcende aos dualismos corpo/alma e corpo/mente (MARTINS, 2015). O corpo revela temporalidades e territórios identitários que funcionam como símbolo cultural para distinguir, agrupar, classificar e ordenar, numa sensibilidade e expressão criativa. Dessa forma, o seu correlato, a corporeidade concebe o corpo como movimento, associando-se à motricidade, à percepção, à linguagem, à sexualidade, aos mitos, à experiência vivida, à poesia do sensível como fenômeno complexo (MARTINS, 2015).

O professor de Educação Física tem um importante papel na desconstrução de idealizações padronizadas de corpos tão cultuadas nos dias atuais. Quando se fala em profissionais que trabalham com o ensino médio, a aproximação dos alunos com o intuito de buscar conhecer suas questões, angústias e interesses, é ainda mais delicada e necessária, dado que a adolescência representa uma etapa de transição e de mudanças corporais (COSTA; SILVA, 2014).

As ações voltadas à imagem corporal na adolescência precisam ser levadas a sério, vistas como uma questão de saúde pública em razão dos problemas cada vez mais recorrentes advindos da insatisfação dos jovens com o corpo. Nesse viés, a escola 
Concepções sobre imagem corporal da mulher negra entre alunas do ensino médio... Francisco Elismar da Silva Junior • Fábio Soares da Costa • Janete de Páscoa Rodrigues

se mostra um ambiente ideal para intervenções de promoção da saúde, necessitando do suporte pedagógico e compromisso dos professores de Educação Física (OLIVEIRA; SANTOS; ROCHA, 2016).

No contexto da imagem corporal entre os jovens, as vivências de experiências de discriminação racial, percebida ou não dessa forma, junto com os conflitos familiares, a insatisfação com o corpo e a pressão externa para se ajustarem a um padrão estético, compõem um quadro de vulnerabilidade, que para cada jovem se manifesta de modo diferente (BITTENCOURT; NUNES, 2017).

\section{Procedimentos metodológicos}

Esta é uma pesquisa de natureza quantiqualitativa, assim, aborda elementos de uma pesquisa qualitativa, ao mesmo tempo que será explicada através dos dados, que serão apresentados de maneira quantitativa. Para Souza e Kerbauy (2017), esse método utiliza a estatística para explicação dos dados e trabalha com as perspectivas das realidades sociais. Também foram empregados os métodos descritivo e estatístico. Para Gil (1999), os estudos descritivos têm como objetivo primordial a descrição das características de determinada população ou fenômeno. Sobre o método estatístico, Thomas, Nelson e Silverman (2007) dizem que a pesquisa estatística pauta-se na interpretação numérica (porcentagens, médias e índices aritméticos, desvio padrão etc.) dos dados obtidos.

Os dados foram coletados a partir de um questionário misto composto por 12 perguntas, elaborado pelos autores conforme objetivo da investigação. Para melhor abordar os sujeitos da pesquisa, as questões seguiram eixos temáticos, como perfil individual das alunas e concepções e percepções acerca da imagem corporal da mulher negra. Foram usadas questões de múltipla escolha e em algumas se pediu que se justificasse a resposta. Desse modo, questionamos às alunas sobre seus entendimentos acerca da imagem corporal da mulher negra. Tal instrumento de coleta foi aplicado no período de março de 2019 em 26 alunas do Ensino 
Concepções sobre imagem corporal da mulher negra entre alunas do ensino médio... Francisco Elismar da Silva Junior • Fábio Soares da Costa • Janete de Páscoa Rodrigues

Médio de uma escola pública de Teresina/PI, com idades entre 15 e 18 anos, as quais foram convidadas diretamente pelos autores a participarem da pesquisa seguindo critérios de voluntariedade e de conveniência dos pesquisadores.

Também se utilizou, na coleta dos dados, uma escala de siIhueta elaborada pelos autores do estudo, composta por 23 imagens de mulheres negras e não negras dispostas em duas colunas. Na primeira coluna pediu-se que as participantes assinalassem a imagem que mais se aproximasse de sua imagem corporal real e na segunda coluna que assinalassem a imagem que elas desejavam ter. Com isso levantou-se a imagem corporal real e ideal apresentada pelas alunas, comparou-se tais imagens assinaladas e cruzamos com as respostas dos questionários.

Antes da aplicação dos instrumentos de coleta de dados foram entregues os TALE (Termos de Assentimento Livre Esclarecido) para as alunas com idade menor que 18 anos e TCLE (Termos de Consentimento Livre Esclarecido) para aquelas que tinham 18 anos ou mais e para os pais/responsáveis das participantes menores de idade, os quais foram devolvidos devidamente assinados por todas as estudantes e pelos responsáveis legais. As participantes foram devidamente esclarecidas sobre os objetivos da pesquisa e a possibilidade de abandonarem o estudo em qualquer momento que desejassem, além de serem informadas que suas identidades seriam mantidas em absoluto sigilo em todas as etapas da investigação e publicação dos resultados.

Para a realização desta pesquisa foram seguidas as diretrizes constantes na Resolução $n^{\circ} 466 / 12$ do CNS do MS. Com isso, a pesquisa foi aprovada pelo Comitê de Ética em Pesquisa com seres humanos da Universidade Federal do Piauí (UFPI), mediante parecer 3.152.316 de 18 de fevereiro de 2019.

Os dados coletados foram submetidos à análise a partir de teorias e conceitos presentes na literatura científica atual. Tais resultados foram ilustrados por meio de imagens para melhor entendimento do estudo. 
Concepções sobre imagem corporal da mulher negra entre alunas do ensino médio... Francisco Elismar da Silva Junior • Fábio Soares da Costa • Janete de Páscoa Rodrigues

\section{Resultados e discussão}

\section{Autopercepção da imagem corporal e a imagem corporal da mulher negra}

Dentre as 26 alunas participantes do estudo, 61,53\% ( $n=16)$ se autoreconheceram como pardas; $19,23 \%(n=5)$ como brancas; $11,53 \%(n=3)$ como negras; 3,84\% ( $n=1)$ como indígena e 3,84\% $(n=1)$ como amarela. Dentre as autodeclaradas negras, todas afirmaram estar satisfeitas com suas características corporais/raciais.

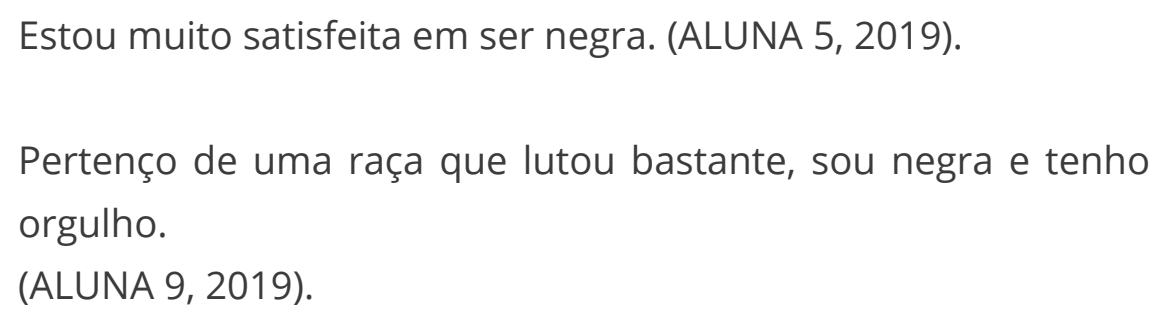

Pertenço de uma raça que lutou bastante, sou negra e tenho orgulho.

(ALUNA 9, 2019).

Entre as que se autodeclaram pardas, 34,61\% ( $n=9)$ disseram que gostariam de ser negras, alegando as seguintes razões:

Porque é uma raça de uma beleza extraordinária e natural. (ALUNA 1, 2019).

Gostaria muito de ser negra, ter os cabelos cacheados, a pele morena.

Acho muito bonito. (ALUNA 7, 2019).

Já 26,92\% ( $n=7)$ afirmaram não desejar ser negras:

Gosto de mim do jeito que sou. (ALUNA 13, 2019).

Nada contra, porém gosto de mim do jeito que sou. (ALUNA 17, 2019). 
Concepções sobre imagem corporal da mulher negra entre alunas do ensino médio... Francisco Elismar da Silva Junior • Fábio Soares da Costa • Janete de Páscoa Rodrigues

No grupo das alunas que se autodeclararam brancas, $11,53 \%$ $(n=3)$ gostariam de ser negras:

Porque eu acho a raça negra muito bela. (ALUNA 10, 2017).

Sou feliz com a "raça" que pertenço, mas não encontraria problemas ou dificuldades em pertencer à outra. (ALUNA 14, 2017).

Sobre a beleza da mulher negra, verificou-se que a maioria das alunas, $88,46 \%(n=23)$ acham as mulheres negras tão bonitas quanto as mulheres das demais raças e $11,53 \%(n=3)$ acham as mulheres negras mais bonitas que as das demais raças. Dentre as justificativas para tais opiniões, estão as seguintes assertivas das alunas:

Porque cada grupo étnico-racial tem a sua beleza natural. (ALUNA 1, 2019).

Porque somos todos iguais e cada um tem suas qualidades na qual os deixam lindos. (ALUNA 5, 2019).

Dentre as justificativas apresentadas por três alunas que consideram as mulheres negras mais bonitas que as demais, estão:

Para mim, o padrão de beleza de muitas mulheres negras é superior às das demais mulheres. (ALUNA 12, 2019).

Porque a cor negra causa diferença entre as demais. (ALUNA 13, 2019).

Ao serem indagadas sobre os aspectos corporais que consideram mais bonito no corpo das mulheres negras, 42,30\% ( $n=11)$ acham a cor da pele; $19,23 \%(n=5)$, as formas do corpo; $15,38 \%$ $(n=4)$, os cabelos; também 15,38\% $(n=4)$ disseram a combinação da cor da pele com os cabelos e 7,69\% ( $n=2)$ acham o conjunto 
Concepções sobre imagem corporal da mulher negra entre alunas do ensino médio... Francisco Elismar da Silva Junior • Fábio Soares da Costa • Janete de Páscoa Rodrigues

de cabelos, cor da pele, formas do corpo e rosto. Sobre aspectos corporais considerados feios, constatou-se que $88,46 \%(n=23)$ não consideram qualquer aspecto como feio; $3,84 \%(n=1)$ afirmou que acha os cabelos feios; $3,84 \%(n=1)$ assinalou o rosto com feio: também 3,84\% ( $n=1)$ marcou outros aspectos.

Diante disso, vê-se que a maioria das alunas não considera qualquer aspecto corporal da mulher negra como feio. Contudo, ainda há poucas opiniões que suscitam alguns estigmas sobre a noção de beleza voltada para padrões europeus, que rejeitam a forma dos cabelos e do rosto das pessoas da raça negra. Percebese que a mídia assume um importante papel na construção da imagem corporal, pois é por intermédio de suas narrativas compostas de sons, imagens e discursos que se formam espaços de criação de sentidos na vida diária, por contribuírem para a constituição de pensamentos e ações dos indivíduos sociais, assim como a corporeidade se apresenta como um arquivo discursivo que simboliza aquilo que uma sociedade deseja ser ou negar (FELIPE; FRANÇA, 2017).

\section{Imagem real e ideal assinaladas pelas alunas na escala de silhuetas}

Para verificar a imagem corporal (real e ideal) foi aplicada uma escala de silhueta, em que foi pedido que as participantes assinalassem as alternativas que mais se assemelhassem a suas imagens corporais reais e ideais. Para análise de estudo focaremos nos resultados com maior ocorrência.

Como imagem corporal real, 19,23\% $(n=5)$ das alunas marcaram "IV" (corpo endomorfo, branca, seios volumosos e com excesso de gordura); no referente à imagem idealizada, a imagem mais assinalada foi "Id" (corpo mesomorfo, branca e bronzeada, musculatura bem definida, cabelos longos e loiros), escolhido por $30,76 \%(n=8)$ das alunas. Destaca-se ainda que 19,23\% $(n=5)$ das 
Concepções sobre imagem corporal da mulher negra entre alunas do ensino médio... Francisco Elismar da Silva Junior • Fábio Soares da Costa • Janete de Páscoa Rodrigues

alunas marcaram como imagens desejadas as mesmas imagens que assinalaram como reais, o que demonstra uma satisfação com sua autoimagem corporal real.

Figura 1: Imagem "Iv", escala de silhueta elaborada pelos autores (2019)

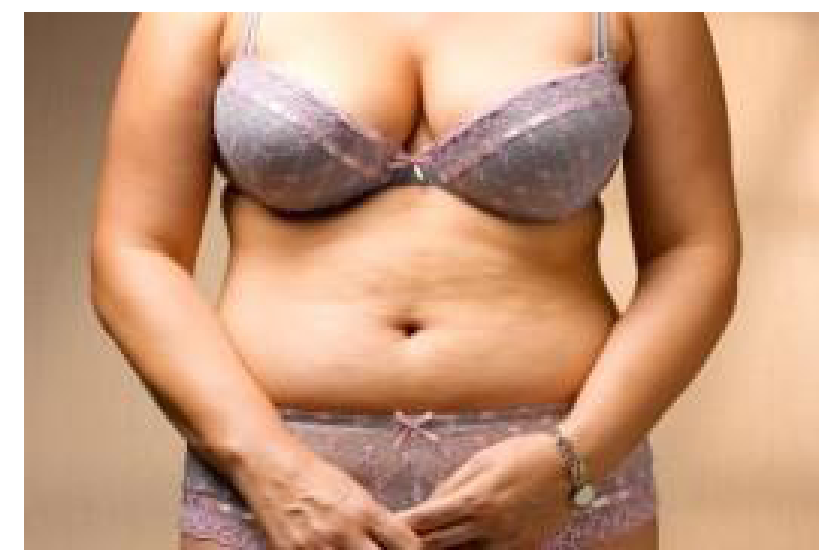

Fonte: Google imagens

Figura 2: Imagem “Id", escala de silhueta elaborada pelos autores (2019).

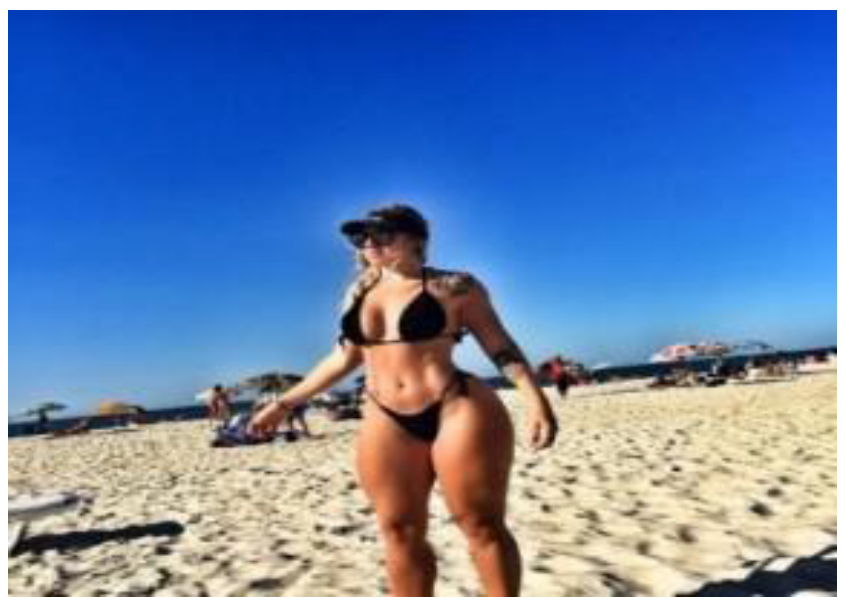

Fonte: Google imagens

Observou-se que as imagens mais assinaladas como imagens reais foram as figuras "IV" e "Iz" ( IV- corpo endomorfo, branca, seios volumosos e com excesso de gordura e Iz-corpo endomorfo, branca, jovem, cabelos ruivos e de médio comprimento, com forma corporal sem definição muscular aparente e sem excesso de gordura corporal). No entanto, $19,23 \%(n=5)$ se autodeclaram 
Concepções sobre imagem corporal da mulher negra entre alunas do ensino médio... Francisco Elismar da Silva Junior • Fábio Soares da Costa • Janete de Páscoa Rodrigues

brancas. Isso demonstra uma possível distorção na autopercepção da imagem corporal dessas alunas.

Desse modo, observamos que $80,76 \%(n=21)$ das pesquisadas apresentaram insatisfação com seu próprio corpo. Segundo Ferreira (2010), o domínio da aparência torna-se "objeto" de barganha nos mercados profissional e sexual, ela representa uma possibilidade de ascensão social, a imagem corporal transforma-se em marca da individualidade, tornando cada vez mais tênue a fronteira entre o individual e o coletivo.

Iannelli e Novaes (2015) também apontam que o aumento da sensação de desconforto em relação ao corpo, à própria imagem corporal e a contínua sensação de inadequação são comportamentos habituais na atualidade. Isso tem levado ao adoecimento em grande escala do sujeito contemporâneo, na qual a mídia tem um papel relevante enquanto fator que propaga a normatização do corpo, manipulando e agenciando subjetividades, enquanto dissemina formas e jeitos de existir hoje por meio do estímulo à reprodução de valores, normas e comportamentos.

Segundo Graup et al. (2008), na fase da adolescência existe uma grande tendência social e cultural de considerar o corpo magro como um ideal para se alcançar aceitação e êxito social, em especial entre as mulheres, o que faz com que grande parte desse público rejeite a sua imagem corporal real.

Entre $61,53 \%(n=16)$ das participantes autodeclaradas pardas; $15,38 \%(n=4)$ se identificaram com a imagem "Iv" (branca e com excesso de adiposidade); 11,53\% ( $n=3$ ) se identificaram como a imagem "IC" (magra de pele "morena"), 11,53\% ( $n=3)$ marcaram imagens de mulheres brancas; $11,53 \%(n=3)$ assinalaram mulheres negras; 7,69\% ( $n=2)$ como na imagem "le"(branca, quadris largos e cintura fina). Levantou-se também que 19,23\% $(n=5)$ gostariam de ter o corpo como na imagem "Id" (branca com musculatura bem definida); $15,38 \%(n=4)$ se declaram satisfeitas; $11,53 \%(n=3)$ gostariam de ter o corpo como na imagem "IC"; 7,69\% (n=2) idealizam um corpo como na imagem "le"; 3,84\% assinalou a imagem "Iz" (branca e magra) e 3,84\% marcou a imagem "II" (magra e negra). 
Concepções sobre imagem corporal da mulher negra entre alunas do ensino médio... Francisco Elismar da Silva Junior • Fábio Soares da Costa • Janete de Páscoa Rodrigues

Observou-se ainda que 3,84\% ( $n=1)$ das alunas que se autodeclararam brancas em resposta ao questionário, assinalou a figura "Ig" (corpo endomorfo, pele negra, cabelo crespo e curto, seios grandes, excesso de gordura corporal) como sua imagem real, o que pode significar uma distorção na construção da imagem corporal dessas alunas.

Dentre $11,53 \%(n=3)$ das alunas que se identificaram como negras 7,69\% $(n=2)$ se perceberam como a imagem "Iv" (corpo endomorfo, branca, seios volumosos e com excesso de gordura). Portanto, todas as alunas desse grupo assinalaram como imagens ideais figuras que representam mulheres magras e brancas. Esses resultados obtidos por meio da escala de imagens corporais revelam contradições por parte de algumas alunas, ao afirmarem no questionário que estão satisfeitas com seus corpos negros.

Ressaltemos que existe uma variedade de formas, biotipos e massa corporal que compõem a diversidade de corpos presentes na sociedade teresinense. Desse modo, pode-se inferir que a insatisfação com a imagem corporal em adolescentes é um problema multifacetado a ser enfrentado por todos os setores da sociedade, mas especialmente o campo educacional e da saúde precisam apresentar estratégias de políticas públicas e de conscientização dos indivíduos adolescentes e jovens sobre os valores e respeito às diferentes formas corporais, etnias e raças. A partir desses ideais de convivência com os diversos corpos nas sociedades, será possível combater-se concepções padronizadas de estéticas corporais amplamente disseminadas pelos meios de comunicação de massa, que pressionam os mais jovens a buscarem obter formas corporais inalcançáveis de beleza (OLIVEIRA; SANTOS; ROCHA, 2016).

A imagem "Id", escolhida pela maioria das participantes como imagem de corpo ideal, revela uma busca por um padrão estético midiático que valoriza o corpo escultural e branco. Nesse cenário, muitas adolescentes apresentaram o desejo de ter um "corpão", padrão de um corpo feminino mais forte e definido. Vê-se, portanto, que a procura por um padrão de imagem corporal não se caracteriza somente pelo corpo magro ou rejeição ao corpo obeso, 
Concepções sobre imagem corporal da mulher negra entre alunas do ensino médio... Francisco Elismar da Silva Junior • Fábio Soares da Costa • Janete de Páscoa Rodrigues

mas especialmente nos dias atuais muitas mulheres vislumbram um ideal de corpo "sarado", representado midiaticamente pelas "mulheres frutas" do funk, atrizes e apresentadoras de TV entre outras.

Nesse sentido, para Bittencourt e Nunes (2017), manifestações não detectáveis pelos testes de triagem podem apontar riscos para problemas de comportamentos alimentares, socioculturais e outros que reforçam a necessidade da compreensão de como essas desordens se mostram em grupos de outras etnias, com outras culturas que vivenciam situações de vida diferentes.

Diante disso, o papel da Educação Física nesse processo de aprendizagem e de construção da cidadania é fundamental para a formação de indivíduos críticos e conscientes de seus reais valores no mundo. Assim, o professor de Educação Física que faz parte de um cotidiano escolar complexo, repleto de políticas públicas com interesses subjacentes, conflitantes, às vezes ilegítimos para a maioria da sociedade, precisa ver-se como um elemento que pode interferir nesse sistema. Para isso, é preciso ter convicção de que a atuação docente pode ajudar a desconfigurar uma tradição didático-pedagógica anacrônica, tecnicista e que não possui mais relação com a função social e democrática da escola contemporânea (MALDONADO, NOGUEIRA; SILVA, 2018).

Nessa linha de pensamento, Maldonado, Nogueira e Silva (2018) defendem que os (as) professores (as) de Educação Física sejam vistos (as) como ferramentas fundamentais na promoção do direito de aprendizagem e de desenvolvimento integral dos (as) estudantes.

\section{Considerações finais}

Conclui-se que as concepções de imagem corporal da mulher negra, manifestadas pelas alunas participantes do estudo, evidenciam estereótipos e preconceitos que historicamente a raça negra sofre e que tais concepções encontram-se permeadas de in- 
Concepções sobre imagem corporal da mulher negra entre alunas do ensino médio... Francisco Elismar da Silva Junior • Fábio Soares da Costa • Janete de Páscoa Rodrigues

certezas e sentidos de beleza fluidos, contraditórios e efêmeros, construídos na ausência de uma educação corporal consistente e capaz de abolir comportamentos e concepções preconceituosas acerca dos convívios das diferentes formas e tons de pele dos corpos num mesmo mundo.

Contudo é evidente a importância do (a) professor (a) de Educação Física assumir seu papel na promoção de ações pedagógicas por meio de conteúdos teórico-práticos da disciplina Educação Física, atuando de forma a desconstruir estigmas preconceituosos por meio de uma Educação Física crítica e libertado$\mathrm{ra}$, desenvolvendo de maneira integral os (as) estudantes ao cultivar com estes sentimentos de respeito aos seus próprios formatos de corpo e aos demais formatos corporais daqueles com quem convivem.

\section{Referências}

ADAMI, F. et al. Aspectos da construção e desenvolvimento da imagem corporal e implicações na Educação Física. Efdeportes/

Revista digital- Buenos Aires, v. 83. 2005. Disponível em: https:// www.efdeportes.com/efd83/imagem.htm. Acesso em: 15 jan. 2019.

BITTENCOURT, L. J.; NUNES, M. O. Transtorno alimentar em estudantes negras de Salvador: a relação com a imagem corporal. DOI: 10.12957/demetra.2017.22141, Demetra: Alimentação, Nutrição \& Saúde, v. 12, n. 1, p. 169-192, 2017. Disponível em: https://www.e-publicacoes.uerj.br/index.php/demetra/article/ view/22141. Acesso em: 20 jan. 2019.

BRASIL. Lei 10.639, de 09 de janeiro de 2003. Institui no currículo oficial da Rede de Ensino a obrigatoriedade da temática História e Cultura Afro-Brasileira. Diário Oficial da União, Brasília, DF, 10 jan. 2003. Disponível em: http://www.planalto.gov.br/ccivil_03/ leis/2003/L10.639.htm. Acesso em: 16 abr. 2019. 
Concepções sobre imagem corporal da mulher negra entre alunas do ensino médio... Francisco Elismar da Silva Junior • Fábio Soares da Costa • Janete de Páscoa Rodrigues

COSTA, S. M. B.; MACHADO, M.T. C. O corpo e a imagem corporal em adolescentes: perspectivas a partir do cuidado integral à saúde. Adolesc. Saúde, Rio de Janeiro, v. 11, n. 2, p. 19-24. 2014. Disponível em: http://www.adolescenciaesaude.com/detalhe_artigo. asp?id=441. Acesso em: 05 dez. 2018.

COSTA, N. T. M.; SILVA, A. C. Corpo e Educação Física escolar no Ensino Médio: a visão dos alunos. Rev. Bras. Ciênc. Esporte, Florianópolis, v. 36, n. 2, p. 223-237. 2014. Disponível em: http:// www.revista.cbce.org.br/index.php/RBCE/article/view/2129. Acesso em: 14 fev. 2019.

FELIPE, D. A.; FRANÇA, F. F. Corporeidade negra nas revistas Veja e Época. Revista NUPEM, Campo Mourão, v. 9, n. 17, p. 86-97. 2017. Disponível em: http://revistanupem.unespar.edu.br/index. php/nupem/article/view/322. Acesso em: 06 fev. 2019.

FERREIRA, F. R. Corpo feminino e beleza no século XX. Rev. ALCEU, v. 11, n. 21, p. 186-201. 2010. Disponível em: http://revistaalceu-acervo.com.puc-rio.br/media/Alceu21_12.pdf . Acesso em: 10 jan. 2019.

FREITAS, R. O. Jovens de Axé: construção de (auto) imagens, estética afro e identidade religiosa. Revista Antropolítica, n. 40, Niterói, p. 81-104. 2016. Disponível em: http://www.revistas.uff. br/index.php/antropolitica/article/view/433. Acesso em: 10 jan. 2019.

GIL, Antônio Carlos. Métodos e técnicas de pesquisa social. 5. ed. São Paulo: Atlas, 1999.

GODOY, K. N. B.; VIEIRA, M. P.; MOURÃO, L. Corpo e mídia na escola: uma análise no portal do professor. Rev. Corpus sci. Rio de Janeiro, v. 11, n. 1, p. 13 - 28. 2015.

GRAUP, S. et al. Associação entre a percepção da imagem corporal e indicadores antropométricos de escolares. Rev. bras. Educ. Fís. Esp., São Paulo, v. 22, n. 2, p.129-38. 2008. Disponível em: http://www.revistas.usp.br/rbefe/article/view/16688. Acesso em: 10 jan. 2019. 
Concepções sobre imagem corporal da mulher negra entre alunas do ensino médio... Francisco Elismar da Silva Junior • Fábio Soares da Costa • Janete de Páscoa Rodrigues

IANNELLI, A. M.; NOVAES, J. V. A dimensão simbólica do corpo e o fenômeno social da corpolatria. DESAFIOS: Revista Interdisciplinar da Universidade Federal do Tocantins, v. 2, n. 01, p. 176-189. 2015. DOI: http://dx.doi.org/10.20873/uft. 2359-3652.2015v2n1p176 p.178. Disponível em: https://www. ssoar.info/ssoar/handle/document/53178. Acesso em: 10 fev. 2019.

MALDONADO, D. T.; NOGUEIRA, V. A.; SILVA, S. A. P. S. Reflexões sobre possibilidades para o desenvolvimen-to da cidadania por meio da educação física no ensino Médio. Pensar a Prática, Goiânia, v. 21, n. 3. 2018. Disponível em: https://www.revistas.ufg. br/fef/article/view/48130. Acesso em: 10 fev. 2019.

MARTINS, E. C. A corporeidade na aprendizagem escolar (Entrelaços fenomenológicos do pensar e agir). Educar em Revista, Curitiba, n. 56, p. 163-180. 2015. Disponível em: https://www.scielo.br/scielo.php?pi$\mathrm{d}=$ S0104-40602015000200163\&script=sci_arttext. Acesso em: 12 fev. 2019.

NOGUEIRA, Isildinha B. O corpo da mulher negra. Pulsional Revista de Psicanálise, v. 13, n. 135, p. 40-45. 1999. Disponível em: https://negrasoulblog.files.wordpress.com/2016/04/o-corpo-da-mulher-negra-isildinha-b-nogueira.pdf. Acesso em: 12 dez. 2019.

OLIVEIRA, A.; SANTOS, A.; ROCHA, L. Educação Física Escolar e Imagem Corporal em Adolescentes: relatos de uma insatisfação. CIAIQ2016, v. 2, 2016. Disponível em: https://proceedings.ciaiq. org/index.php/ciaiq2016/article/view/802. Acesso em: 02 out. 2017.

SILVA, C. R. R. Beleza negra, orgulho crespo: no corpo (des) constrói-se a (in) diferença, o estigma. Projeto História: Revista do Programa de Estudos Pós-Graduados de História, v. 56, 2016. Disponível em: https://revistas.pucsp.br/revph/article/view/25602. Acesso em: 02 jan. 2019. 
Concepções sobre imagem corporal da mulher negra entre alunas do ensino médio... Francisco Elismar da Silva Junior • Fábio Soares da Costa • Janete de Páscoa Rodrigues

SILVA, F. A. G.; SILVA, L. A. I.; LÜDORF, S. M. A. A Educação Física no Ensino Médio: um olhar sobre o corpo movimento. Rev. Movimento, Porto Alegre, v. 21, n. 3, p. 673-686. 2015. Disponível em: http://seer.ufrgs.br/index.php/Movimento/article/ view/53026/39203. Acesso em: 02 jan. 2019.

SOUZA, Kellcia Rezende. KERBAUY, Maria Teresa Miceli. Abordagem quanti-qualitativa: superação da dicotomia quantitativa-qualitativa na pesquisa em educação. Educação e Filosofia. v. 31, n. 61, p. 21-44. Uberlândia, 2017. Disponível em: http://200.19.146.79/index.php/EducacaoFilosofia/article/ view/29099. Acesso em: 02 jan. 2019.

THOMAS, J.R.; NELSON, J.K.; SILVERMAN, S.J. Métodos de pesquisa em atividade física. $5^{\mathrm{a}}$ ed. Porto Alegre: Artmed. 2007.

\section{Publisher}

Universidade Federal de Goiás. Faculdade de Educação Física e Dança. Publicação no Portal de Periódicos UFG. As ideias expressadas neste artigo são de responsabilidade de seus autores, não representando, necessariamente, a opinião dos editores ou da universidade. 